\title{
О ПРАВОВОЙ ПРИРОДЕ И ПРАВОВОМ РЕГУЛИРОВАНИИ ПУБЛИЧНОГО ПРЕДЛОЖЕНИЯ
}

\begin{abstract}
Аннотация: Настоящая статья посвящена известному, однако не востребованному в должной мере институту отечественного договорного права - заключению договора посредством публичного предложения. $B$ статье производится анализ правовой природы и правового регулирования публичного предложения как одной из форм заключения договора. Автором обосновывается отграничение заключения договоров посредством публичного предложения от публичной оферты, торгов. Наибольшего распространения заключение договоров посредством публичного предложения получило в сфере продажс государственного и муниципального имущества. Основываясь на эффективности использования публичного предложения в сфере продажи имущества и заключения договоров, в статье рассматривается и обосновывается возможность использования публичного предложения в качестве способа заключения государственных и муниципальных контрактов. Автор проводит комплексный анализ возможностей применения данного способа в государственных и муниципальных закупках. Обосновывается вывод о возможности применения публичного предложения как способа закупок без проведения торгов. Предлагается ряд мер по усовершенствованию правового регулирования в исследуемой сфере

Abstract: This paper considers a well-known but not much sought-after institution of Russian contract law - the formation of a contract through a public offering. It presents an analysis of the legal nature and legal regulation of public offers as a type of contract creation. The author establishes differences between concluding contracts through a public offering and doing so via option contracts or competitive tenders. Contracts created by means of public offering are mostly seen in the sale of state and municipal property. Given the efficient use of public offerings in the sale of property and contract creation, the article discusses the possibility of using public offerings as a way to create state and municipal contracts. The author carries out a comprehensive analysis of the possibilities of using this method for the purposes of state and municipal procurement. He concludes that it is possible for public offerings to be used as a method of procurement without the need for a competitive tendering process, and proposes a number of measures to improve legal regulation in this area.
\end{abstract}

Ключевые слова: торги, государственный контракт, государственные закупки, приватизация, Юриспруденция, оферта, муниципальный контракт, договор, имущество, публичная оферта

Keywords: competitive tender, government contract, government procurement, privatization, jurisprudence, offers, options contract, contract, property, options contract.

T рактика заключения договоров посредством публичного предложения, безусловно, заслуживает пристального изучения. Данный способ уже успел положительно себя зарекомендовать в сфере приватизации государственного и муниципального имущества. Его эффективность объясняется, с одной стороны, защитой интересов собственника имущества, позволяющей продать его по максимально выгодной в сложных экономических условиях цене. С другой стороны, продажа посредством публичного предложения позволяет хозяйствующему субъекту, желающему приобрести определенное имущество, но не обладающему большим запасом денежных средств, стать его собственником, уплатив за покупку приемлемую для себя цену, адекватную состоянию рынка.

Вместе с тем вопрос о правовой природе и правовом регулировании продажи имущества посредством публичного предложения является в науке отечественного гражданского права малоизученным.

Говоря о публичном предложении, прежде всего, отметим, что эта дефиниция означает один из способов отчуждения имущества, принадлежащего как публичным образования, так и частным лицам. При этом в сфере публичного и в сфере частного права действует разное законодательство. В первом случае речь идет о приватизации государственного (муниципального) имущества, и такие отношения регулируются Федеральным законом от 21 декабря 2001 года № 178-Ф3 «О приватизации государственного и муниципального имущества» (далее - Закон о приватизации) и Положением об организации продажи государственного или муниципального имущества посредством публичного предложения (утв. постановлением Правительства РФ от 22 июля 
DOI: $10.7256 / 1811-9018.2013 .11 .2330$

При цитировании этой статьи сноска на доі обязательна

\section{Право и политика $11(166) \cdot 2013$}

2002 года № 549¹. Если же речь идет о продаже имущества посредством публичного предложения через призму частного права, то среди всего выделим случаи продажи имущества должника в процессе конкурсного производства, а также продажу невостребованной вещи из ломбарда. Достойны упоминания и многочисленные факты объявления продажи имущества посредством публичного предложения частными лицами.

Заметим при этом, что единое правовое регулирование процедуры публичного предложения в сфере частного и публичного права отсутствует. Этим обстоятельством, безусловно, определяется актуальность и необходимость систематизации законодательства о публичном предложении. Однако прежде исследуем вопросы правовой природы публичного предложения. Наиболее полный ответ на них дает Закон о приватизации, устанавливающий, что публичное предложении о продаже государственного (муниципального) имущества является публичной офертой (часть 1 статьи 23).

В силу пункта 2 статьи 437 ГК РФ публичной офертой является содержащее все существенные условия договора предложение, из которого усматривается воля лица, делающего предложении, заключить договор на указанных в предложении условиях с любым, кто отзовется. Таким образом, исходя из положений действующего гражданского законодательства, а также отечественной цивилистики публичное предложение применительно к приватизации государственного (муниципального) имущества - это предложение заключить договор приватизации, которое, во-первых, достаточно определено и выражает явное намерение публичного образования заключить договор, во-вторых, обращено к неопределенному кругу лиц, и в-третьих, содержит все существенные условия договора приватизации.

Казалось бы, налицо идентичность признаков публичного предложения и публичной оферты, однако, на наш взгляд, не является корректным в полной мере отождествлять публичное предложение и публичную оферту. Также не кажется нам верным заявление, что публичная оферта именуется в законодательстве о приватизации публичным предложением².

\footnotetext{
${ }^{1}$ В отношении организации продажи имущества, находящегося в государственной собственности субъектов РФ и в муниципальной собственности указанное Положение является примерным. Таким образом, правовое регулирование продажи имущества посредством публичного предложения осуществляется также законодательством субъектов РФ и муниципальными правовыми актами.

${ }^{2}$ См.: Гражданское право: учебник: в 2 т. Т. 1 / под. ред. О.Н. Садикова. М., 2006. С. 367.
}

Как известно, не существует разницы, в какой форме (устной, письменной, электронной...) выражается оферта, важен лишь факт появления окончательно сформировавшегося намерения стороны заключить договор. Применительно к приватизации в качестве содержащего все существенные условия договора предложения, из которого усматривается воля лица заключить договор с любым, кто отзовется (т.е. публичной оферты по смыслу статьи 447 ГК РФ), выступает информационное сообщение о продаже государственного (муниципального) имущества.

В силу статей 15,23 Закона о приватизации информационное сообщение публикуется организатором продажи имущества, оно адресовано неограниченному кругу лиц, содержит все условия договора купли-продажи, признаваемые законодательством существенными (наименование имущества и позволяющие индивидуализировать его данные, а в определенных случаях, цена имущества либо способ ее определения). Наконец, в информационном сообщении указывается наименование государственного органа, органа местного самоуправления, принявшего решение об условиях приватизации имущества, реквизиты указанного решения, а также способ приватизации, что, на наш взгляд, явно свидетельствует о намерении заключить договор купли-продажи.

Вместе с тем не стоит забывать, что законодатель в статье 13 Закона о приватизации относит публичное предложение к способам продажи имущества наряду с, например, торгами. Поскольку сущностью публичного предложения является заключение договора приватизации с заявителем, первым подавшим в установленный срок заявку на приобретение имущества по цене предложения, то считаем обоснованным рассматривать публичное предложение как способ заключения договора.

Таким образом, говоря о публичном предложении, необходимо иметь в виду двойственную природу указанного понятия. С одной стороны, публичное предложение являет собой сам способ заключения договора приватизации государственного и муниципального имущества, его процедура, с другой стороны, под публичным предложением подразумевается непосредственно предложение заключить договор приватизации (оферта), содержащееся в информационном сообщении о продаже государственного (муниципального) имущества.

В то же время на практике и в теории отечественного гражданского права все активнее задается вопрос, является ли публичное предложение формой торгов либо между ними есть различия. Представляется, что указанные сомнения стали следствием путаной по- 
литики законодателя, с одной стороны, объявившего публичное предложение публичной офертой, а с другой стороны, относящего публичное предложение к формам проведения торгов ${ }^{3}$. Кроме того, существуют случаи отнесения публичного предложения к формам торгов и в судебной практике ${ }^{4}$.

Как известно, в силу норм ГК РФ торги как способ заключения договора могут проводиться в форме аукциона или конкурса. Таким образом, исходя из формально юридической точки зрения законодатель, не упоминая публичное предложение среди форм проведения торгов, не относит его к ним. Заметим также, что в силу статьи 23 Закона о приватизации продажа имущества посредством публичного предложения осуществляется в случае, если аукцион по продаже имущества был признан несостоявшимся. Согласно законодательству о несостоятельности (банкротстве) имущество должника подлежит продаже посредством публичного предложения в случае, если повторные торги по продаже имущества должника признаны несостоявшимися (часть 4 статьи 139 Федерального закона «О несостоятельности (банкротстве)»). Считаем, что со стороны законодателя было бы неразумным проводить торги в одной форме (продажа имущества посредством публичного предложения) в случае признания несостоявшимися торгов (иногда - повторных), проведенных в иной форме (аукцион). Указанное суждение находит свое подтверждение и в судебной практике 5

Одним из аргументов сторонников отнесения публичного предложения к формам торгов служит схожесть информационного сообщения, публикуемого при продаже имущества посредством публичного предложения, и извещения о проведении аукциона (конкурса). Однако информационное сообщение, как было указано выше, является публичной офертой в силу названных причин, тогда как вокруг вопроса, является ли извещение о проведении торгов офертой, ведутся

${ }^{3}$ Согласно ч. 2 ст. 13 Федерального закона от 19.07.2007 № 196-Ф3 «О ломбардах» в случае объявления торгов по реализации невостребованной вещи несостоявшимися ломбард вправе провести повторные торги путем публичного предложения (здесь и далее - курсив автора). Согласно ч. 4 ст. 139 Федерального закона от 26.10.2002 № 127-Ф3 «О несостоятельности (банкротстве)» в случае продажи имущества должника посредством публичного предложения публикуется сообщение о проведении торгов.

${ }^{4}$ См.: Постановление ФАС Северо-Кавказского округа от 12.09.2008 № Ф08-5144/08 // СПС «КонсультантПлюс».

${ }^{5}$ См.: Определение ВАС РФ от 22.06.2007 № 7095/07 // СПС «КонсультантПлюс»; Постановление ФАС Центрального округа от 07.05.2007 по делу № А14-9783-2006/410/4 // СПС «КонсультантПлюс». ожесточенные споры ${ }^{6}$. Заметим лишь, что одним из доводов противников отождествления извещения о проведении торгов и оферты является затруднительность положения участников торгов, чьи предложения уже направлены, но еще не получены организатором торгов в случае, когда последний уже получил заявку от участника и у него возникла обязанность заключить с ним договор7. В то же время такая ситуация является характерной для продажи имущества посредством публичного предложения. Право приобретения имущества принадлежит лицу, первому акцептовавшему оферту организатора продажи указанного имущества. Остальные акцепты (заявки) не рассматриваются, более того, они даже не принимаются и не регистрируются (часть 5 статьи 23 Закона о приватизации).

Таким образом, налицо явное различие правовой природы исследуемых объектов. Кроме того, считаем, что относить извещение о проведении торгов к числу оферт не совсем верно хотя бы потому, что оно не всегда содержит все существенные условия договора, например, цены в случае продажи недвижимости. Также говоря о цене, следует отметить, что если при проведении торгов цена напрямую зависит от действий участников торгов, то в случае продажи посредством публичного предложения цена имущества определяется организатором продажи в одностороннем порядке, а потенциальные покупатели могут лишь следить за ее изменением и акцептовать публичное предложение.

Следующим отличием публичного предложения от торгов видится нам характер правоотношений, которыми связаны организатор и участники продажи посредством торгов и публичного предложения, а также собственник продаваемого имущества и организатор продажи.

Говоря о продаже имущества посредством публичного предложения, структура указанных отношений преобразуется в двухзвенную. Договоры между организатором и участниками продажи и договор с победителем соединяются, поскольку, во-первых, в указанном случае победитель не определяется, договор заключается с первым подавшим заявку по цене предложения в установленный срок. Во-вторых, в отличие от договора о проведении торгов, где под страхом незаключенности договора необходимы акцепты хотя бы двух участников, для признания договора продажи

\footnotetext{
${ }^{6}$ См.: Кукла М.Е. Заключение договора на торгах // Право и политика. 2007. № 3. С. 143-144.

${ }^{7}$ Гражданское право: учебник: в 3 т. Т. 1. Отв. ред. А.П. Сергеев,
} Ю.К. Толстой. М., 2004. С. 611. 
DOI: $10.7256 / 1811-9018.2013 .11 .2330$

При цитировании этой статьи сноска на доі обязательна

\section{Право и политика $11(166) \cdot 2013$}

имущества посредством публичного предложения заключенным достаточно одного акцепта (заявки), даже если он окажется единственным.

Наконец, ключевым отличием публичного предложения от торгов является разница самой правовой природы указанных явлений. Так, М.И. Брагинский, говоря о заключении договора путем публичного предложения (публичной оферты) отмечает, что «... из двух конститутивных признаков торгов - публичности и состязательности при продаже имущества посредством публичной оферты сохраняется только один - публичность. В этом случае признак состязательности отсутствует. Такой вывод можно прямо усмотреть в части 5 статьи 23 Закона о приватизации. Особое значение имеет содержащееся там же указание: «После регистрации первой заявки прием заявок прекращается». Таким образом, вопрос о состязательности заведомо снимается» ${ }^{8}$.

Таким образом, на наш взгляд, публичное предложение следует отличать от института торгов и выделять его в отдельную юридическую конструкцию, имеющую двойственную правовую природу: как форму продажи имущества и как публичную оферту. Стоит также заметить, что правовое регулирование предмета нашего исследования пока не видится нам упорядоченным массивом правовых норм. Считаем, что связано это, прежде всего, с отсутствием его цельности, зачастую противоречивые нормы, регулирующие продажу имущества посредством публичного предложения, рассредоточены по многочисленным нормативным правовым актам разной юридической силы. Выходом из слоившейся ситуации нам представляется включение норм, характеризующих правовую природу публичного предложения, в ГК РФ.

Кроме того, оставление разрешения вопроса о том, кто имеет право на подачу первой заявки, а значит, и на заключение договора купли-продажи, на усмотрение организатора продажи имущества посредством публичного предложения видится нам необоснованным решением законодателя. Указанная ситуация противоречит принципам равенства участников гражданских правоотношений и открытости деятельности органов государственной власти и органов местного самоуправления. Законодателем не предусмотрено, на основании каких критериев должна определяться заявка, подлежащая регистрации в качестве первой, что влечет за собой значительное увеличение опасности коррупционных проявлений в деятельности организаторов продажи

\footnotetext{
${ }^{8}$ Брагинский М.И. Конкурс. М., 2005. С. 43-44.
}

имущества посредством публичного предложения. По данному вопросу существует также весьма неоднозначная судебная практика9.

Итак, публичное предложение в современных экономических условиях представляется нам одним из наиболее эффективных способов реализации любого имущества. Являясь вынужденной мерой, обусловленной отсутствием потенциального коммерческого интереса к подлежащему продаже имуществу, продажа имущества посредством публичного предложения находит свое применение во многих сферах экономической жизни государства и общества.

Между тем сфера применения публичного предложения может быть значительно расширена, прежде всего, за счет государственных и муниципальных закупок. На первый взгляд, ответ на вопрос, уместно ли публичное предложение как способ заключения государственных или муниципальных контрактов, должен быть отрицательным, так как публичное предложение и существующие способы размещения заказов для публичных нужд преследуют разные цели. Если первый способ - это один из примеров «торгов продавца», когда организатором торгов выступает продавец имущества, заинтересованный в скорейшей его продаже, то второй является в чистом виде «торгами покупателя», в которых выигравшим лицом является покупатель вещи, заинтересованный в максимальном снижении цены.

Вместе с тем на практике встречаются ситуации, когда государственный или муниципальный заказчик заинтересован не столько в максимальном уменьшении цены на покупаемый товар, но на скорейшее его приобретение за приемлемую цену. В этом случае заказчику целесообразно установить свои требования и просто ожидать первого участника размещения заказа, акцептующего оферту заказчика. Дополнительным аргументом в пользу возможности применения такого порядка служит сравнительно короткий срок проведения всей процедуры.

Однако, с другой стороны, нельзя сказать, что публичное предложение обладает какими-либо преимуществами перед имеющимися способами размещения государственных и муниципальных заказов. Так, проведение запроса котировок и заключение договора с единственным поставщиком также занимает меньше времени по сравнению с традиционными конкурсами и аукционами. А в случае заключение договора с един-

\footnotetext{
${ }^{9}$ См., например: Постановление ФАС Северо-Западного округа от 04.03.2008 по делу № А 05-7200/2007 // СПС «КонсультантПлюс», Постановление ФАС Московского округа от 21.12.2006 по делу № КГ-А40/12078-06 // СПС «КонсультантПлюс».
} 
DOI: $10.7256 / 1811-9018.2013 .11 .2330$

При цитировании этой статьи сноска на dоі обязательна

Правоведение

ственным поставщиком срок размещения заказа может составить считанные дни. Кроме того, в случае запроса котировок заказчик может рассчитывать на снижение начальной (максимальной) цены. Таким образом, налицо превосходство в эффективности данных способов над публичным предложением.

В этой связи единственным возможным способом применения публичного предложения остается размещение заказов в случае, если конкурс или аукцион были признаны несостоявшимися, так как в конкурсную (аукционную) комиссию поступила лишь одна заявка или участником конкурса (аукциона) был признан лишь одно лицо. В данном случае в силу норм Закона о размещении заказов государственный или муниципальный контракт заключается с единственным участником по начальной (максимальной)) цене. Таким образом, фактически имеет место процедура заключения договора посредством публичного предложения. Заказчик заключает договор с первым (и единственным) откликнувшимся на предложение участником.

Между тем, как было замечено ранее, публичное предложение является способом заключения договора наравне с торгами. В этой связи оно не может быть частью торгов - иного способов заключения договора. Торги не являются родовым понятием по отношению к видовому - публичное предложение. Полагаем, торги, равно как и публичное предложение, являются видовыми терминами по сравнению с родовым - способ заключения договора. Наконец, коррупциогенность публичного предложения вследствие наличия у заказчика эксклюзивного права определять победителя и влиять на возможность подачи заявок, на наш взгляд, не позволяет использовать его в случае, если торги были признаны несостоявшимися ввиду отсутствия заявок на участие или самих участников. Теоретически заказчик мог бы объявить публичное предложение на покупку товаров и назначить цену покупки, однако на практике это породило бы огромную волну злоупотреблений при размещении заказов, заключающихся в намеренном осложнении подачи заявок сторонними конкурентами и, наоборот, облегчении процедуры для аффилированных, «своих» участников.

Таким образом, использование публичного предложения в современной системе размещения заказов на поставку товаров для государственных или муниципальных нужд фактически сводится в применении данной процедуры в случае объявления торгов несостоявшимися вследствие подачи лишь одной заявки или признания лишь одного лица участником торгов. В этом случае публичное предложение может быть использовано в государственных и муниципальных закупках как заключение контракта (договора) с первым откликнувшимся лицом на условиях, изложенных в предложении.

Таким образом, полагаем, публичное предложение как способ заключения договора заслуживает включения в перечень способов государственных и муниципальных закупок без проведения торгов.

\section{Библиография:}

1. Брагинский М.И. Конкурс. М., 2005.

2. Гражданское право: учебник: в 2 т. Т. 1 / под. ред. О.Н. Садикова. М., 2006.

3. Гражданское право: учебник: в 3 т. Т. 1. Отв. ред. А.П. Сергеев, Ю.К. Толстой. М., 2004

4. Кукла М.Е. Заключение договора на торгах // Право и политика. 2007. № 3. С. 139-148

\section{References (transliteration):}

1. Braginskii M.I. Konkurs. M., 2005.

2. Kukla M.E. Zaklyuchenie dogovora na torgakh // Pravo i politika. 2007. № 3. S. 139-148 